CAROLINA BORI RECEBE O TÍTULO DE DOUTORA HONORIS CAUSA PELA

UNIVERSIDADE DE BRASÍLIA

CAROLINA BORI RECEIVES THE TITLE OF DOCTOR HONORIS CAUSA BY

UNIVERSITY OF BRASÍLIA

\author{
Maria Angela Guimarães Feitosa ${ }^{2}$ \\ UNIVERSIDADE DE BRASÍLIA, BRASIL
}

\begin{abstract}
RESUMO
O texto reproduz saudação feita a Carolina M. Bori em cerimônia na qual foi agraciada com o título de Doutora Honoris Causa pela Universidade de Brasília, em reconhecimento pelos relevantes serviços prestados à psicologia e à ciência brasileira. São destacados aspectos de sua formação, de seu papel no desenvolvimento da Psicologia como área de conhecimento e de ensino, seu papel na divulgação do conhecimento científico e na política científica em geral no Brasil. São ainda registrados a amplitude do reconhecimento de seu trabalho, e um depoimento sobre Carolina como professora, colega e ser humano.

Palavras-chave: Carolina Bori, psicologia brasileira, ciência brasileira, Universidade de Brasília.
\end{abstract}

\begin{abstract}
The text reproduces the address of salutation to Carolina M. Bori in ceremony in which she was granted the title of Doctor Honoris Causa, in recognition for the relevant services to Brazilian psychology and science in general. The text outlines Carolina's education, stresses her contributions to the development of scientific policies for the advancement of Psychology and its teaching in Brazil, to the diffusion of scientific knowledge in general and its advancement in Brazil. The text also registers the breath of recognition of Carolina's work as well as a personal testimony of Carolina as professor, colleague, and human being.
\end{abstract}

Key words: Carolina Bori, Brazilian psychology, Brazilian science, University of Brasília.

O Conselho Universitário da Universidade de Brasília faz, através desta cerimônia, a outorga do título de Doutora Honoris Causa a Carolina Martuscelli Bori, em reconhecimento aos relevantes serviços prestados à comunidade científica, notadamente à Psicologia e à ciência brasileira.

A decisão do Conselho Universitário foi pautada, não só pela análise de um impressio- nante currículo, como pelo conhecimento direto do trabalho de Carolina. Foi ainda facilitada por uma publicação editada por Maria Amélia Matos na qual 51 pessoas depõem acerca de Carolina. Não só impressiona a expressão dos depoentes e a variedade da natureza da contribuição referida, mas o fato de que os depoentes são oriundos de várias instituiçôes e

\footnotetext{
1 Reprodução de saudação a Carolina M. Bori, feita em sessão solene de outorga, realizada em Brasília, no dia 27 de outubro de 2000 . A concessão do título foi proposta conjuntamente pela Reitoria e pelo Instituto de Psicologia da Universidade de Brasília, e a cerimônia de outorga foi integrada à programação da XXX Reunião Anual de Psicologia da Sociedade Brasileira de Psicologia, estando Carolina rodeada por vários de seus colaboradores e ex-alunos, além de professores, alunos e servidores da Universidade de Brasília.

2 Endereço para correspondência: Universidade de Brasília, Instituto de Psicologia, 70910-900 Brasília DF. E-mail:afeitosa@unb.br. Agradeço ao Prof. Dr. Lauro Morhy, Reitor da Universidade de Brasília, pela permissão para divulgação ampla do documento.
} 


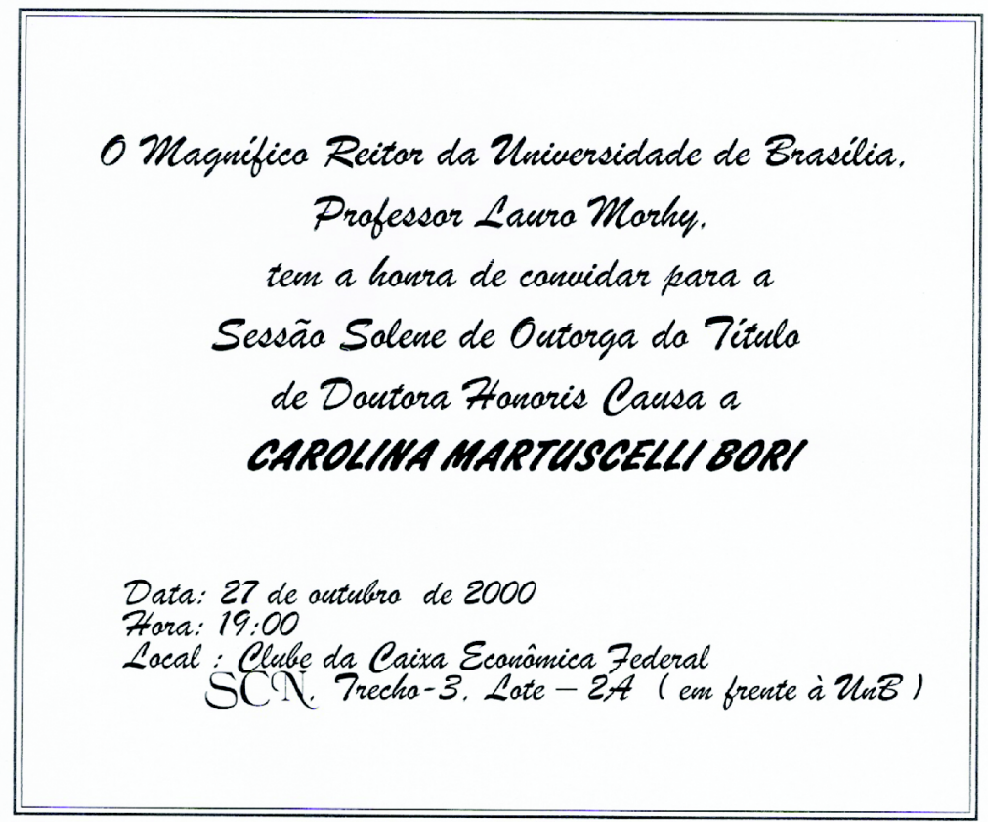

Figura 1 - Imagem do convite distribuído pelo Cerimonial da Universidade de Brasília para a cerimônia de homenagem a Carolina Bori.

áreas do conhecimento, num claro testemunho de que Carolina não nos pertence com exclusividade. Nós a partilhamos de forma ampla com a ciência brasileira e a educação universitária brasileira. Nós a partilhamos em esfera mais ampla ainda com o ensino da psicologia.

Sinto-me honrada por aqui representar o Instituto de Psicologia da Universidade de Brasília, porque reconheço nele as marcas que Carolina lhe imprimiu quando, em 1964, atendeu a convite para coordenar a implantação do Departamento de Psicologia. Sinto-me também honrada porque, neste momento, posso partilhar um pouco com cada um de vocês o significado de ter sido aluna de Carolina e sua companheira de trabalho.

A trajetória de Carolina mostra uma ferrenha luta pelo desenvolvimento da ciência brasileira e uma constante preocupação com a sociedade brasileira. De sua preocupação central com a psicologia brasileira como ciência e profissão decorre sua atenção sistemática ao ensino de Psicologia. Muitas coisas se iniciaram em Psicologia com a participação central de Carolina. Como a relação é grande, serei seletiva ao analisar a trajetória de sua carreira.

\section{A FORMAÇÃO}

Formada em Pedagogia pela Faculdade de Filosofia, Ciências e Letras da Universidade de São Paulo em 1947, integrou a primeira geração de graduados formados pela primeira geração de professores brasileiros da Universidade de São Paulo. Fez seu mestrado sob a orientação de Tamara Dembo, na New School for Social Research em Nova York, onde se aprofundou na teoria de campo de Kurt Lewin, tendo em 1952 defendido dissertação. Fez seu doutorado na Universidade de São Paulo, sob a orientação de Anita Cabral, e em 1954 defendeu tese sobre a teoria da motivação de 
Lewin, dando continuidade aos estudos iniciados no mestrado. Entrou em contato com a obra de Skinner em 1948, ainda numa época em que, por orientação de Anita Cabral, a Gestalt era hegemônica na Universidade de São Paulo, e veio a intensificar seu contato com o behaviorismo com a primeira vinda de Fred Keller ao Brasil em 1961.

\section{A POLÍTICA CIENTÍFICA DA ÁREA DE PSICOLOGIA}

Tendo sido presidente da Associação Brasileira de Psicologia, de 1954 a 1955 e novamente de 1963 a 1965, e da Sociedade de Psicologia de São Paulo de 1960 a 1961, Carolina ajudou a criar estas duas entidades e, no exercício dessas presidências, teve participação central na regulamentação da profissão de psicólogo no país e na concepção do decreto lei que determina o currículo mínimo para a formação em Psicologia. Esta história precisa ser mais bem conhecida pela geração contemporânea, pois envolveu uma discussão importantíssima sobre a natureza da atividade do psicólogo e de sua formação. A aparentemente singela exigência, na lei 4.119 de 1962, de que o curso de Psicologia deve ser ministrado na $\mathrm{Fa}$ culdade de Filosofia, representa a vitória da posição de que a formação do psicólogo deve estar calcada na ciência e mais especificamente na pesquisa básica. Provavelmente a Psicologia seria diferente hoje se a conclusão da discussão tivesse sido outra.

Foi ainda presidente da Associação de Modificação do Comportamento, de 1969 a 1973, fundadora e primeira presidente da Associação Nacional de Pesquisa e Pós-graduação em Psicologia, de 1984 a 1986, e primeira Presidente da Sociedade Brasileira de Psicolo- gia, de 1992 a 1993, num claro reconhecimento da Sociedade de Psicologia de Ribeirão Preto de sua liderança científica. Como João Cláudio Todorov bem lembrou ontem, a Sociedade tinha a liderança de Ribeirão Preto, mas a participação de pesquisadores, professores e alunos de um grande número de estados brasileiros.

\section{O ENSINO DE PSICOLOGIA}

Carolina teve participação decisiva na criação de cursos, disciplinas ou laboratórios de psicologia em várias Universidades públicas brasileiras. Em Rio Claro: Em 1959 passa a lecionar psicologia em instituição que viria futuramente a integrar a UNESP. Em Brasilia: $\mathrm{Na}$ Universidade de Brasília, foi responsável pela implantação do Curso de Psicologia, em 1964.

Este último episódio foi revestido de profundas implicações, que em muito transcenderam a criação de um curso e de um laboratório. Definiu, no novo curso, a marca duradoura da indissociabilidade entre o ensino e a pesquisa; e entre a formação profissional e a pesquisa básica em Psicologia. Pôs em prática uma nova forma de ensinar com a ajuda de preciosos colaboradores que tão bem soube escolher e cativar, dentre eles Fred Keller, com quem passa a ter uma interlocução de vida, na qual comungam a atenção ao aluno. Faz parte da história da Universidade de Brasília que este trabalho amplamente estimulado por Darcy Ribeiro foi interrompido por fatos políticos e Carolina, junto com um grande número de professores de outras áreas, nos deixou antes do previsto. Mas a semente foi bem plantada e, apesar das cicatrizes da agressão que sofreu, a Universidade de Brasília se ergueu, ainda com as marcas de seus fundadores. O fato de Caro- 
lina ter sido convidada para integrar o Conselho Diretor da Fundação Universidade de Brasília em 1992, e ainda integrá-lo ${ }^{3}$, reflete, entre outras coisas, o reconhecimento pela sua profunda identificação com os ideais desta Universidade, que se iniciou por ocasião da implantação do curso de Psicologia.

Continuando, em São Paulo: Na Universidade de São Paulo, em 1968, ajudou a criar e estruturar o Departamento de Psicologia Social e Experimental do Instituto de Psicologia. Este fato integra um marco importante na concepção da estrutura da Universidade, que foi a queda da cátedra. Junto com o professor Walter Hugo Cunha, idealizou e implantou o curso de pós-graduação em Psicologia Experimental daquele Instituto, do qual foi coordenadora por 15 anos, assegurando sua consolidação e liderança na formação de pesquisadores e quadros para o ensino de psicologia. Foi nesta fase da carreira de Carolina que fui aluna sua. Em animadíssimas discussões nas aulas sobre Táticas de Pesquisa aprendemos que a avaliação de dados experimentais é um problema empírico, que não pode ser separada nem dos próprios dados, nem das técnicas que os tornam possíveis.

Ainda, em Salvador: Criado o curso de Psicologia na Universidade Federal da Bahia em 1968, Carolina é convidada a orientar a criação de seu Laboratório de Psicologia Experimental. Este convite representou o início de uma longa interação entre Carolina e o curso de Psicologia em Salvador, com repercussões para a formação de docentes para outros cursos de Psicologia no Nordeste. Em São Carlos: A Universidade Federal de São Carlos convida-a para trabalhar no Centro de Educação e Ciên- cias Humanas, do qual veio a ser Diretora entre 1976 e 1979. De sua manifesta preocupação com a formação do professor surge a decisão de criar um Curso de Mestrado em Educação Especial, que ela idealizou e organizou nessa Universidade. Mais tarde Carolina volta a colaborar com a Universidade Federal de São Carlos, na concepção de seu curso de graduação em Psicologia, no qual se reconhece a forte proposição da vinculação da formação profissional à pesquisa. Em Belém: Participou das discussōes de criação do Mestrado em Análise do Comportamento na Universidade Federal do Pará. Em Natal: Assessorou a Pró-Reitoria de Pesquisa e Pós-Graduação da Universidade Federal do Rio Grande do Norte na criação de núcleos de Pesquisa.

\section{A DIVULGAÇÃO DO CONHECIMENTO CIENTÍFICO}

Carolina exerceu papel central na criação de periódicos científicos, e no estabelecimento de seu patamar de qualidade, não só em Psicologia, como em âmbito mais abrangente. Exerceu papel central também no desenvolvimento e na preservação de variados mecanismos para trazer a ciência para o cidadão e para a criança, como, por exemplo, a Estação Ciência em São Paulo.

\section{A POLÍTICA CIENTÍFICA EM GERAL ATRAVÉS DA SBPC}

Tendo formalmente iniciado sua participação na Sociedade Brasileira para o Progresso da Ciência em 1969, na função de Conselheira, assumiu ininterrupta e sucessivamente funçōes cada vez mais importantes nesta Sociedade,

3 Esta colaboração só veio a se encerrar com seu falecimento. 
chegando à função de Presidente de 1985 a 1989, e finalmente a Presidente de Honra, desde 1989. Nessas funções, e em outras que também exerceu, foi uma crítica ferrenha do regime político militar e uma incansável defensora da democracia e dos direitos humanos.

\section{A AMPLITUDE DO RECONHECIMENTO DO IMPACTO DO TRABALHO DE CAROLINA}

Não só esta cerimonia reflete o reconhecimento amplo do valor e do impacto da carreira de Carolina, mas reitera a marca de pioneirismo em sua carreira. Ela é a primeira mulher a ser agraciada com o título de Doutora Honoris Causa pela Universidade de Brasília, dignificando de forma muito especial a mulher brasileira. Poucos meses atrás a Sociedade Brasileira para o Progresso da Ciência a homenageou, junto com Anísio Teixeira. A Associação Americana de Psicologia recentemente o fez, em reconhecimento a sua contribuição para o ensino de Psicologia. O governo brasileiro recentemente também o fez, reconhecendo seu compromisso maior com o país.

\section{CAROLINA HOJE}

Dentre as várias atividades que Carolina presentemente exerce, está a participação na Comissão de Especialistas em Ensino de Psicologia, e em especial na formulação das Diretrizes Curriculares para o curso de Psicologia e no estabelecimento de critérios para a avaliação do ensino de Psicologia no país, por convite do Ministério da Educação. Este é o contexto no qual tive a honra de colaborar com Carolina nos últimos quatro anos. Gostaria de partilhar com vocês minha observação de que, quanto mais complexa a tarefa, mais prazeroso é trabalhar com Carolina, não só por suas qualidades pessoais, como pela clareza de princípios e objetivos, pela capacidade de ouvir, pela exigência com a lógica e a argumentação, pela inesgotável capacidade de trabalho.

Carolina me permitiu compartilhar momentos preciosos: a dignidade no sofrimento pessoal, a humildade quando do reconhecimento público de seu valor, o bom humor e o interesse pelo ser humano, o profundo senso de propriedade na escolha de estratégias para lidar com fatos políticos. Alguém já disse que a Psicologia precisaria de umas quatro ou cinco Carolinas. Daria muito trabalho, mas como seria bom para a Psicologia!

Carolina, continuamos precisando muito de você. Em nome do Instituto de Psicologia,

Muito obrigada!

\section{REFERÊNCIAS}

Matos, M. A. (Ed.) (1998). Psicologia USP. 9 (1). Psicologia e Ciência no Brasil.

SBPC (1998). Cientistas do Brasil. São Paulo: Sociedade Brasileira para o Progresso da Ciência.

Trujillo, J. P. (2000). Regulamentação da profissão de psicólogo: pequeno estudo histórico. Trabalho apresentado no VII Encontro Regional da ABRAPSO, em Piracicaba, 12 a 14 de outubro de 2000. 


\section{IBAC - CURSOS DE ESPECIALIZAÇÃO COM INÍCIO EM 2006}

- Curso de Especialização em Análise Comportamental Clínica (reconhecido pelo CFP/ABEP)

- Início: 11 de fevereiro de 2006

- Aulas aos sábados: $9 \mathrm{~h}$ às $12 \mathrm{~h}$

- Duração: 2 ou 3 anos, conforme opção do aluno

- Carga horária: 540h incluindo teoria e prática

- Vagas limitadas.

- Curso de Especialização em Terapia Analítico-Comportamental Infantil ${ }^{*}$

- Início: abril de 2006

- Coordenação: Dra Laércia Abreu Vasconcelos

- Aulas uma vez por mês (sábado e domingo/manhã e tarde).

- Duração: 2 anos

- Carga horária: 540h incluindo teoria e prática

- Vagas limitadas.

* Em processo de regulamentação

- Cursos de extensão são periodicamente divulgados no site.

INSCRIÇÕES: OnLine www.ibac.com.br ou diretamente na

Sede do Instituto: 910 Sul-MIX PARK SUL, bloco F, salas 119 a 129. Brasília, DF

Fones: $3242-5250$ e 3443-4086 